\title{
DESCRIPTIONS OF SEVEN NEW SPECIES OF ACHATINA FROM THE CONGO FREE STATE.
}

By S. I. Da Costa.

Read 11th January, 1907.

PLATE XX.

TuE writer is indebted to Mrr. George Grey for his kindness in sending him several interesting shells from the southern part of the Congo State, about $10^{\circ} 30^{\prime} \mathrm{S}$. lat., between the watershed of the Lualaba and Lufira rivers. Among them are the following seren species of Achatina. Although they differ materially in form and texture from one another, their general characteristics are somewhat similar, the writer therefore refrains from making comparisons between them and the species of other authors. His most cordial thanks are due to Mr. E. A. Smith for the valuable assistance afforded him in the investigations rendered necessary before undertaking the descriptions of these new species.

Achativa Greyr, n.sp. Pl. XX, Fig. 1.

Testa fusiformi-orata, subventricosa, imperforata, tenuis, straminca, strigis fulguratis latis fuscis, in anfractu ultimo ad basim productis ornata; anfractus $7 \frac{1}{2}$, parum conrexi, longitudinaliter striati, priores minutissime granulati, ultimus fortiter reticulatus, son lonitudinis rquans; sutura subcrenulato-marginata ; apex obtusus; columella leviter torta, oblique truncata; apcrtura oralis, intus lactea; peristoma simplex, acutum. Long. 58, diam. $32 \mathrm{~mm}$.; apertura $32 \mathrm{~mm}$. longa, 15 lata.

Achatisa ofata, n.sp. Pl. XX, Fig. 2.

Testa orata, rentricosa, imperforata, tenuissima, fulra, strigis pallide brunneis fulguratis ornata ; anfractus 7, longitudinaliter rugoso-striati, priores minutissime granulati, ultimus $\frac{3}{3}$ longitudinis xquans, striis infra medium eranidis; apex obtusus; sutura subcrenulata; columella recta, alba, leviter torta, abrupte truncata; apertura oblongo-oralis, intus cærulco-lactea; peristoma simplex, acutum. Long. 56, diam. $32 \mathrm{~mm}$.; apertura $30 \mathrm{~mm}$. longa, 16 lata.

Achatina traxsparens, n.sp. Pl. XX, Fig. 3.

Testa oblongo-orata, imperforata, tenuissima, nitida, diaphana; anfractus 7, longitudinaliter subplicato-striati, priores sub lente minutissime granulati, fuscescentes, strigis castaneo-brunneis undatim fulguratis picti; ultimus $\frac{3}{5}$ longitudinis æquans; apex obtusus ; sutura impressa ; columella recta, abrupte truncata ; apertura parum obliqua, semioralis, intus margaritacea, peristoma simplex, acutum. Long. 51, diam. $23 \mathrm{~mm}$. ; apertura $26 \mathrm{~mm}$. longa, 12 lata. 



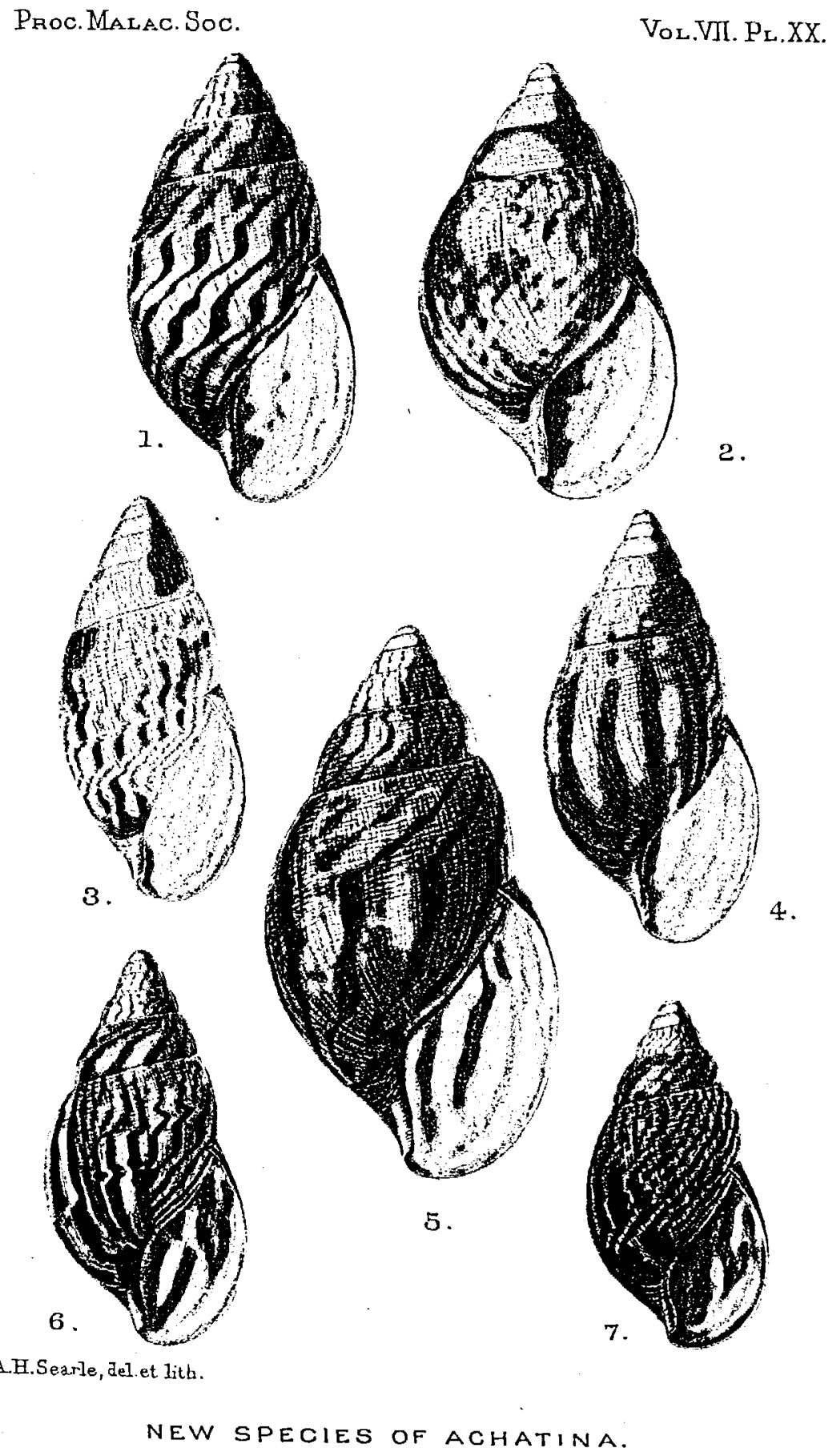


Acratins subovats, n.sp. Pl. XX, Fig. 4.

Testa oblongo-orata, subrentricosa, imperforata, crassiuscula, straminea, strigis latis castaneis ornata; anfractus 7, longitudinaliter subtiliter striati, undique granoso-decussati; ultimus. $\frac{3}{5}$ longitudinis æquans; spira conica; apex obtusiusculus; sutura subcrenulata; columclla recta, leviter torta, oblique truncata, carulea; apertura oblongo-ovalis, intus lactea; peristoma simplex, acutum. Iong. 55, diam. $20 \mathrm{~mm}$.; apertura $28 \mathrm{~mm}$. longa, 14 lata.

Achativa zforisa, n.sp. Pl. XX, Fig. 5 .

Testa orato-fusiformis, subventricosa, imperforata, tenuis, straminea, strigis latis fuscis ornata; anfractus 7, longitudinaliter striati, undique granoso-decussati; ultimus spiram paulo superans; apex obtusatus; sutura subcrenulata; columella alba, subcontorta, abrupte truncata ; apertura oralis, intus cæruleo-lactea; peristoma simplex, acutum. Long. 70, diam. $38 \mathrm{~mm}$.; apertura $38 \mathrm{~mm}$. longa, 18 lata.

Achativa riggolata, n.sp. Pl. XX, Fig. 6.

Testa fusiformi.orata, subrentricosa, imperforata, tenuis, straminea, strigis latis fulminatis nigricante-castaneis ornata; anfractus 7 , longitudinaliter rugoso-striati, priores sub lente minutissime granulati; ultimus $\frac{3}{5}$ longitudinis requans, infra medium obsolete decussatulus; spira conica; apex obtusiusculus; sutura impressa; columella recta, leriter torta, oblique truncata, cerulea; apertura angulato-oralis, intus albida, strigis translucentibus; peristoma simplex, acutum. Long. 50, diam. $27 \mathrm{~mm}$; apertura $25 \mathrm{~mm}$. longa, 13 lata.

Achatrus obscona, n.sp. Pl. XX, Fig. 7.

Testa orato-conica, tenuiuscula; imperforata, castanea, strigis fulminatis saturate fulris et nigris variegata; anfractus 7 , convexiusculi, longitudinaliter striati, priores sub lente minutissime granulati; ultimus $\frac{3}{8}$. longitudinis xquans, infra medium obsolete decussatulus; spira conica; apex obtusiusculus; sutura marginata; columella cæruleo-alba, subcontorta, oblique truncata; apertura oblongo-oralis, intus cæruleo-alba; peristoma simplex, acutum. Long. 44, diam. $23 \mathrm{~mm}$.; apertura $23 \mathrm{~mm}$. longa, 12 lata.

Explatation OF PLATE XX.

Fra. 1. Achatina Greyi, n.sp.

"2. ", orata, n.sp.

$"$ "3. " " transparens, n.sp.

"4. " " subotata, n.sp.

"

"

"7. " ", obscura, n.sp. 